DOI: $\underline{10.20472 / T E .2015 .3 .3 .006 ~}$

\title{
WHEN PROFESSIONAL IDENTITY MEETS PRAXIS: A QUALITATIVE STUDY OF CHILD AND YOUTH CARE STUDENTS
}

\author{
REBECCA STILLER, JULIE MASSON, STEPHEN NEUMAN NEUMAN, \\ SAMANTHA DRYNAN, LAURIE FEEHAN, CASSAUNDRA COOMBS, BAILEY \\ SMITH, CURTIS WEST, GERARD BELLEFEUILLE, LISA STIKSMA
}

\begin{abstract}
:
A critical issue in Child and Youth Care (CYC) education is the development of a professional CYC identity. Students are often caught between the potentially conflicting roles of fitting into a perceived CYC identity archetype and developing their personal approach to CYC praxis. This qualitative study examined the ways in which CYC students perceive and experience constructs of identity in the field of CYC as well as the ways that they respond internally to such constructs. The research design utilized creative modes of inquiry both in the processes by which the research was conducted and in the methods used to represent research data. The combination of traditional data collection strategies with arts-based presentation methods provided the participants a powerful learning experience by opening up a meaning-making space. This meaning making generated important insights into and understandings of the politics of identity in relation to the development of the participants' unique sense of CYC praxis.
\end{abstract}

\section{Keywords:}

archetype, child and youth care, identity, arts-based, praxis

\section{Authors:}

REBECCA STILLER, MacEwan University, Canada, Email: bellefeuilleg@macewan.ca JULIE MASSON, MacEwan University, Canada, Email: massonj5@macewan.ca STEPHEN NEUMAN NEUMAN, MacEwan University, Canada, Email: neumans@macewan.ca SAMANTHA DRYNAN, MacEwan University, Canada, Email: drynans2@macewan.ca LAURIE FEEHAN, MacEwan University, Canada, Email: feehanl2@macewan.ca CASSAUNDRA COOMBS, MacEwan University, Canada, Email: coombsc5@macewan.ca BAILEY SMITH, MacEwan University, Canada, Email: smithb232@macewan.ca CURTIS WEST, MacEwan University, Canada, Email: westc12@macewan.ca GERARD BELLEFEUILLE, MacEwan University, Canada, Email: bellefeuilleg@macewan.ca LISA STIKSMA, MacEwan University, Canada, Email: stiksmal@macewan.ca

\section{Citation:}

REBECCA STILLER, JULIE MASSON, STEPHEN NEUMAN NEUMAN, SAMANTHA DRYNAN, LAURIE FEEHAN, CASSAUNDRA COOMBS, BAILEY SMITH, CURTIS WEST, GERARD BELLEFEUILLE, LISA STIKSMA (2015). When Professional Identity Meets Praxis: A Qualitative Study of Child and Youth 
Care Students. International Journal of Teaching and Education, Vol. III(3), pp. 75-84., 10.20472/TE.2015.3.3.006 


\section{Introduction}

The field of Child and Youth Care (CYC) is not only more diverse than ever before but that diversity itself is growing more diverse. In today's global world, professional identities are not only more complex and fluid than they used to be, reflecting shifting cultural interests and differences. For those of us interested in the concept of praxis as a form of agency that encourages CYC practitioners to use creativity, to challenge existing practices, to take risks, and to develop their own unique approaches, the assumption that the development of professional identity and the development of personal praxis are mutually constitutive bears further examination.

\section{Background}

The concept of praxis as a way of knowing, doing, and being, which is grounded in a responsible, ethical, self-aware, and accountable process of action and interaction (see White, 2008), is brought into focus in the first year of CYC study.

Arguably the most influential thinker about education in the late twentieth century, Paulo Freire defined praxis as the vehicle through which we not only critically evaluate our own position in the world, but a transformative lens through which we come to perceive and understand ourselves as moral agents (Freire, 1970).

Yet, despite the faculty's best efforts to help students to develop their unique sense of CYC praxis by encouraging critical thinking, creative expression, risk taking, and ethical sensitivity to issues of social justice, CYC students have expressed a tension between fitting into a prescribed but implicit CYC identity archetype and challenging the status quo within the field of practice. The experience of not fitting the archetype has resulted in a sense of being an outsider and, in a small number of cases, to a decision to leave the program.

\section{Research Method}

CYC's ontology is informed by the belief that knowledge is embedded in social relationships and is contextualized within one's social and cultural environment.

As a result, the research design was situated within a constructivist interpretivist paradigm, which is founded on the theoretical belief that reality is socially constructed and fluid (Rossman \& Rallis, 2003). The interpretivist approach seeks explanation of the social world at the level of subjective experience (Merriam, 1998). Consistent with the interpretive perspective, an exploratory qualitative research design was adopted in this study.

The research design was embedded in a critical theoretical perspective. The notion of research as praxis is a basic tenet embraced by researchers working within any of the critical research paradigms. As such, research informed by critical theory is particularly concerned with exposing hidden power imbalances (Kincheloe \& McLaren, 2003). Applied to education, research informed by critical theory focuses on raising the conscious awareness of educators about the values and beliefs that underpin their seemingly natural teacher-centred classroom roles (Taylor, 2008). 


\section{Research Question}

The focus of this research was to explore the perceptions and experiences of CYC students regarding the integration of personal praxis and professional CYC identity formation. Accordingly, the study was derived using the following research questions:

1. Does a CYC identity archetype exist?

2. If so, do students feel that their praxis "fits" within the confines of that archetype?

3. Does the perception of a CYC archetype impact one's commitment to praxis?

\section{Sampling}

A non-probability criterion-based sampling technique was used to select participants in the study with maximum variation according to gender, age, years and level of related work experience, and years enrolled in the CYC program. Non-probability sampling represents a range of sampling techniques that help researchers select units from a population that can "purposefully inform an understanding of the research problem and central phenomenon [of] the study" (Creswell, 2007, p. 125). A total of 9 CYC students took part in the study. Approximately thirty percent of the participants were third-year transfer students.

\section{Data Collection}

Data collection is an important aspect of any study. In consideration of the theoretical assumptions that underpin CYC praxis and the research aim to investigate the perceptions and lived-experiences of CYC students, a three-pronged approach to data collection was used. It comprised semi-structured focus groups, arts-based self-expression (Bellefeuille, Ekdahl, Kent, \& Kluczny, 2014), and participant observation. The participants were randomly divided into two separate cohorts (Cohort A and B), although five participants were members of both cohorts.

\section{Cohort A}

Cohort A was asked to choose from 47 words cut-out and spread across a table in no particular order (refer to Table A).

\section{Table A}

CYC Identity/Praxis Word List

\begin{tabular}{lllll}
\hline Agency & Guidance & Helping & Attachment & Vulnerable \\
Life Space & Empowerment & Community & Reconciliation & Development \\
Communication & Rehabilitation & Advocacy & Control & Crisis \\
Outreach & Rescuing & At-risk & Trauma & Awareness \\
\hline
\end{tabular}




\begin{tabular}{lllll}
\hline Connection & OBSD & Professional & Creativity & AWOL \\
Quality & Protect & Partnership & Therapeutic & Mindfulness \\
Juvenile & Oppression & Reliability & Growth & Care \\
Treatment & Behaviour & Role Model & Mentoring & Praxis \\
Systems & Interventions & Confidentiality & Feminist & Postmodern \\
Child Development & Self-Expression & & & \\
\hline
\end{tabular}

The selected words represented common terminology, concepts, values, and beliefs that the researchers felt represented a CYC identity archetype and CYC praxis. Participants were given blank slips of paper with which to contribute additional words that, for them, represented CYC. Research Cohort A was than instructed to decide as a group which words most and least represented a CYC identity archetype by placing the words in two boxes labelled "praxis" and "CYC Identity." These boxes (see Figure 1) symbolized what language is common or promoted within a CYC context and which words are not, and thereby defining roles, rules, and expectations for workers within a CYC archetype.

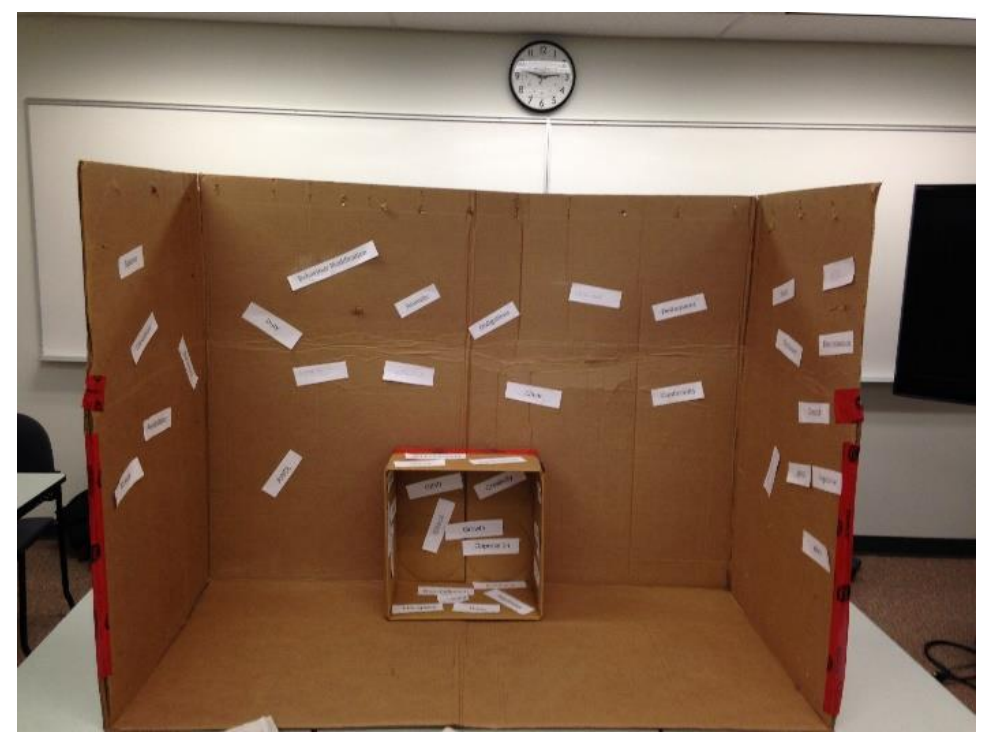

Figure 1. Boxes.

The activity concluded with researchers and participants collectively exploring the decisions and the decision-making processes regarding their choices to insert words into the respective boxes in the form of a semi-structured focus group.

\section{Cohort B}

Cohort B took part in an activity that encouraged participants to express their perception of a CYC archetype in a creative way, through the creation of visual collages (see Figure 2). Participants were provided with various craft supplies and were asked to create individual 
collages that represented their expression of themselves as a CYC practitioner; this activity helped to highlight individuals' self-perceptions in the context of Child and Youth Care.

The researchers then encouraged participants to discuss the elements of their collage that were most sacred to them as practitioners, as well as their thoughts about what elements of their own praxis they see reflected in or excluded from the dominant discourses surrounding identity in Child in Youth Care. Through discussion, the cohort developed a loose definition of a CYC identity archetype and actively compared their expressions of praxis with that construct. The session concluded with an open discussion regarding participants' collages, the process of collage creation, and the reciprocal impact of professional identity on praxis.

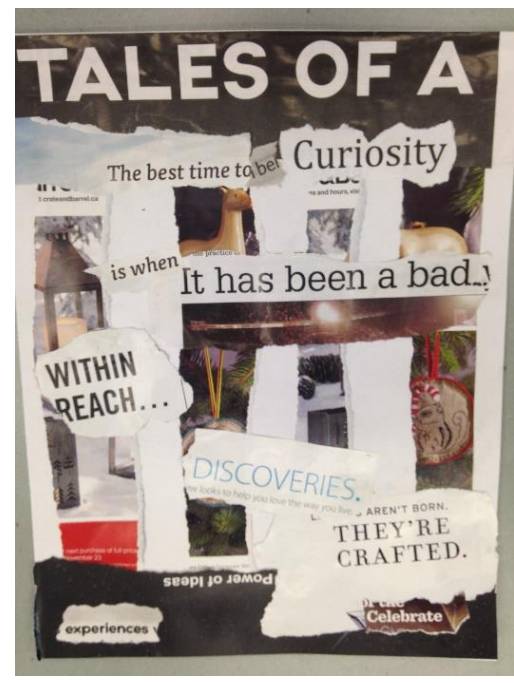

Figure 2. Example of visual collage.

Combining traditional data collection strategies with arts-based methods of expression offered the participants a powerful learning experience by opening up a meaning-making space that enabled important insights into and understandings of the politics of identity in relation to the development of their unique sense of CYC praxis.

\section{Data Analysis Methodology}

The data collection and data analysis were conducted concurrently. Data were analysed using a 6-step iterative process that included becoming familiar with data, generating initial categories or meaning units, searching for themes, reviewing themes, defining and naming themes, and producing a report (Braun \& Clarke 2006, p. 87).

Step 1: The eight-member research team, divided into two sub-groups of four members each, disseminated the recordings from the research sessions. Each researcher began by conducting an initial read and thematic analysis.

Step 2: One of the four-person research subgroups then collectively conducted a thematic analysis for data collected from Cohort $A$ and the other four members of the research team 
formed the second subgroup and conducted the collective thematic analysis for data collected from Cohort B.

Step 3: The research team met as a whole to define identified themes while discussing possible relationships between emerging ideas. This collaboration produced the final and most intensive thematic analysis.

Step 4: Using the written reflections and notes from group meetings, the research team developed a written report summarizing the qualitative results that emerged from the thematic analyses.

\section{Findings}

Study findings illuminated the challenges students faced in forming a personal approach to CYC praxis while aligning themselves with a professional CYC identity archetype within a formative environment. The data analysis revealed three major themes: identity constraint, mixed identity formation, and identity related ethical dilemmas.

1. Identity Constraint: Participants indicated that the CYC archetype was only a partial representation of their personal CYC identity, and that certain elements of identity (particularly faith and spirituality) were consistently believed not fit into the archetypal model. It was also noted by participants that despite being able to identify an archetype, they were not threatened by its presence. In fact, there was a general comfort with the presence of an archetype as long as there was no pressure to fit into it.

Mixed Identity Formation: The majority of participants indicated that their identity formation stemmed from the past (experience, people, spirituality). In other words, participants noted less impact on their identity formation by the CYC program than was hypothesized. The participants also recognized and articulated the intent of professors to shape identity with language. Specifically, the students could identify key words used by instructors and the instructors' proposed intent in using them. Success in the program was discussed as being linked to students' capacity to interpret and take on the key language of CYC.

2. Students who accepted identity constructs and displayed understanding of certain language were reinforced in their efforts, leading to greater focus on CYC-specific language and personality attributes. Interestingly, this impact occurred even when participants' own acceptance of that language and those attributes was lacking. Other students identified times when they expressed their personal praxis in the classroom or in assignments by challenging the philosophies that were being taught or even styles of teaching. These students noted feeling dismissed or treated as rebellious and therefore felt disempowered in their attempts to defy norms, which lead to some confusion about where formation and expression of personal praxis was acceptable. Participants indicated that challenging established professionals in the field was encouraged but that challenging professors was implicitly discouraged.

3. Ethical Dilemmas: Several elements of the CYC archetype were labelled as "good" by participants (for example, non-judgement, empowerment, and acceptance). Furthermore, in many cases students had thoughtfully evaluated these constructs and values and sought 
to incorporate them into their personal ethical framework. Nevertheless, although students described much of what was included in the CYC archetype as being positive, they expressed discomfort with the actual idea of an archetype. They appreciated the values but not the limitations that accompanied them. Students also struggled ethically with the sense that in subscribing to the CYC archetype as a whole, they had somehow sacrificed some integrity of thought, belief, or articulation. Student-practitioners shared their experiences within the field when they found the archetype they had accepted was not adopted or did not "fit" within their working environment. Participants seemed to prefer the idea of picking and choosing the archetypal elements that fit their view of their praxis, rather than accepting all components without discrimination.

What emerged from the activities was a shared understanding that students are aware of a possible identity archetype, that the archetype impacts students in subtle ways, and that ethical dilemmas may result from a lack of cohesion between identity archetype and personal praxis. Thus, these three themes can be considered to form the foundation of these students' lived experiences of CYC identity.

\section{Rigour}

The research team used established standards of rigor (trustworthiness, dependability, and credibility) to enhance the transparency of the process (reference). Trustworthiness was assured by discussing the methods, design, analysis, results, and conclusions as a research team. Dependability was established by documenting the thematic analysis process and confirming each decision with other team members. These steps ensured consistency throughout the process of data collection and data analysis. Credibility was ensured by first identifying and then bracketing the personal assumptions and biases of the research team prior to the start of the data analysis.

\section{Dissemination}

The findings of the study were shared at a research showcase hosted at MacEwan University (see Figure 3).

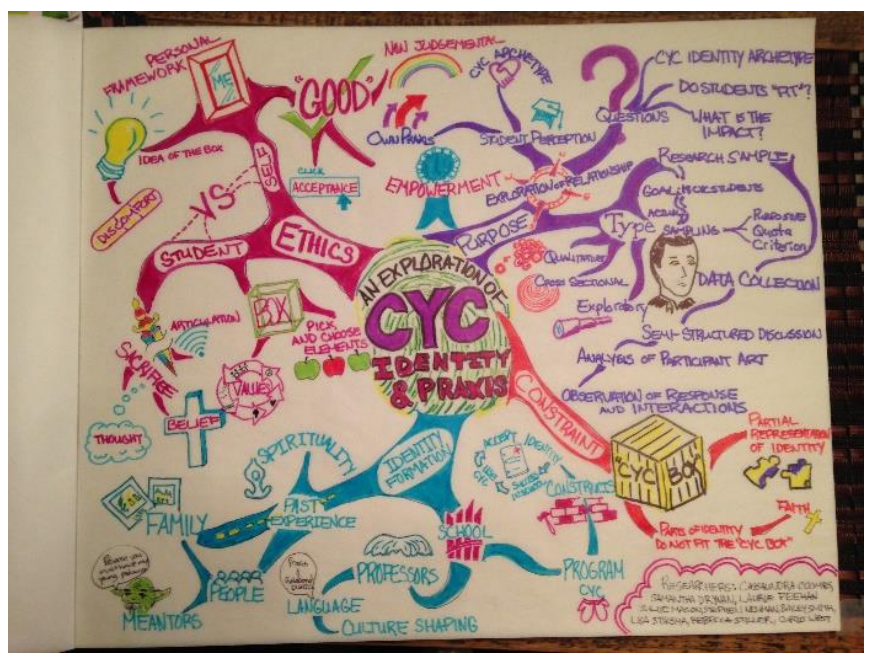

Figure 3. Research poster. 
In keeping with the arts-based and interpretive approach utilized by the researchers, three members of the research team designed a dissemination poster that used mind-mapping and association to communicate key points and to showcase findings. Because the research showcase took place in a common area of the university, the research poster was designed with visual interest in mind. The researchers emphasized the flow of knowledge and the connections between research concepts, while avoiding a strictly linear representation of their results. During the showcase, the researchers fielded questions from professors, colleagues, and the general public, and they explained both the process of the research and the findings it generated. The researchers worked collaboratively through this process to effectively communicate their research results and their overall reflections on the research process.

\section{Discussion}

This study explored the relationship between student practitioners' perceptions of the identity archetype associated with CYC practitioners, and of their internal perceptions of CYC praxis in the context of CYC education and practice. The researchers' goal was to explore a deeper understanding of the lived experience of student practitioners in this area, rather than to define or solve any problem that this understanding might pose. The results of the study showed that student practitioners do perceive and react to a CYC identity archetype. Additionally, it suggested that student practitioners recognize that their "fit" within an archetype, especially in terms of language, can impact their success within both a CYC post-secondary program and the CYC workforce. The results also demonstrated students' partial acceptance of an archetype. However, this acceptance was tempered by students' ethical concerns about the presence of an identity archetype on the whole.

As one of the most important critical educators of the $21 \mathrm{~h}$ century, Freire (2000) has noted:

Education either functions as an instrument which is used to facilitate integration of the younger generation into the logic of the present system and bring about conformity or it becomes the practice of freedom, the means by which men and women deal critically and creatively with reality and discover how to participate in the transformation of their world. (p. 34)

The supported creation of individual praxis fits ideally into Freire's pedagogical model, but a prescribed archetype stands in direct contrast and, it could be argued, that such an archetype is itself an oppressive regiment. The intention of the research design was to explore and expose whether a chasm exists between what is professed about the program and the reality that students experienced subjectively.

The limitations of this study include its sample size and diversity of research participants. These limitations resulted from time constraints and the class-based nature of this research project. With additional time, more information could have been collected from more students at a greater number of educational institutions. Further investigation into the nature of the impact of a CYC identity archetype on individual praxis is warranted; such research could lead to best-practice strategies for post-secondary CYC programs, 
promoting authentic inclusivity and thereby potentially increasing the investment of students in their CYC education.

\section{References}

Bellefeuille, G., Ekdahl, C., Kent, L. Kluczny, M. (2014). A Course-Based Creative Inquiry Approach to Teaching Introductory Research Methods in Child and Youth Care Undergraduate Education. International of Teaching and Education, 2(2). 1-9.

Braun, V. \& Clarke, V. (2006). Using thematic analysis in psychology. Qualitative Research in Psychology, 3(2), 77-101.

Freire, P. (2000). Pedagogy of the oppressed. New York: Continuum.

Kincheloe, J., \& McLaren, P. (2003). Rethinking critical theory and qualitative research. In N. Denzin\&Y. Lincoln (Eds.), Handbook of qualitative research: Theories and issues (2nd ed., pp. 279-314). Thousand Oaks, CA: Sage.

Merriam, S. B. (1998). Qualitative research and case study applications in education. San Francisco: JosseyBass.

Rossman, G. B., \& Rallis, S. F. (2003). Learning in the field: An introduction to qualitative research (2nd ed.). Thousand Oaks, CA: Sage.

Taylor, P. C. (2008). Multi-paradigmatic research design spaces for cultural studies researchers embodying postcolonial theorising. Cultural Studies in Science Education, 4(3), 881-889.

White, J. (2008). The knowing, doing and being in context: A praxis-oriented approach to child and youth car. In Bellefeuille, G. and Ricks, F. (Eds.) Standing on the precipice: Inquiry into the creative potential of child and youth care practice (pp. 109-134). Edmonton, AB: MacEwan Press. 